\title{
PRODUTIVIDADE DO MILHO EM CONDIÇÕES DE DIFERENTES MANEJOS DO SOLO E DE DOSES DE NITROGÊNIO ${ }^{(1)}$
}

\author{
Claudinei Kappes ${ }^{(2)}$, Orivaldo $\operatorname{Arf}^{(3)}$ \& João Antonio da Costa Andrade ${ }^{(4)}$
}

\begin{abstract}
RESUMO
Pesquisas têm sido desenvolvidas buscando identificar a melhor dose de $\mathbf{N}$ para o milho nos mais diferenciados sistemas de manejo do solo. Contudo, não há ainda concordância quanto aos resultados, pois a dinâmica desse nutriente é influenciada pelo manejo do solo e pelas coberturas vegetais. $O$ objetivo deste trabalho foi avaliar a produção de matéria seca e acúmulo de nutrientes em coberturas vegetais e produtividade do milho em sucessão, submetidos a diferentes manejos do solo e de doses de $\mathbf{N}$. Os experimentos foram conduzidos no município de Selvíria, MS, durante os anos agrícolas 2009/2010 e 2010/2011, sob Latossolo Vermelho distrófico típico argiloso. Foram estabelecidos 36 tratamentos com quatro repetições, em blocos casualizados, resultantes da combinação de coberturas vegetais (milheto, Crotalaria juncea e milheto + Crotalaria juncea), manejo do solo (preparo com escarificador + grade "leve", grade "pesada" + grade "leve" e sistema plantio direto) e doses de $N$ em cobertura $\left(0,60,90\right.$ e $120 \mathrm{~kg} \mathrm{ha}^{-1}$ - ureia como fonte). $\mathrm{O}$ híbrido de milho utilizado foi o DKB $350 \mathrm{YG}^{\circledR}$ e o $\mathrm{N}$, aplicado no estádio $\mathrm{V}_{5}$ (quinta folha expandida). Ocorreu incremento linear do índice de clorofila foliar, teor de $\mathbf{N}$ foliar, comprimento e diâmetro de espiga, massa de 1.000 grãos e produtividade, com o aumento nas doses de $\mathrm{N}$ em cobertura. A utilização de crotalária e de milheto + crotalária como antecessoras, associada à aplicação de $120 \mathrm{~kg} \mathrm{ha}^{-1}$ de $\mathrm{N}$ em cobertura, proporcionou maior produtividade do milho após dois anos agrícolas.
\end{abstract}

Termos de indexação: Zea mays, milheto, crotalária, adubação nitrogenada, produtividade.

(1) Parte da Tese de Doutorado do primeiro autor apresentada à Universidade Estadual Paulista - UNESP. Recebido para publicação em 19 de junho de 2012 e aprovado em 11 de julho de 2013.

(2) Pesquisador, Fundação MT, Centro de Pesquisa Dario Minoru Hiromoto. Av. Antônio Teixeira dos Santos, 1559, Parque Universitário. Caixa Postal 79. CEP 78750-000 Rondonópolis (MT), Brasil. E-mail: claudineikappes@fundacaomt.com.br

(3) Professor Titular, Departamento de Fitotecnia, Tecnologia de Alimentos e Sócio-Economia, UNESP. Avenida Brasil, 56, Centro. CEP 15385-000 Ilha Solteira (SP), Brasil. E-mail: arf@agr.feis.unesp.br

(4) Professor Titular, Departamento de Biologia e Zootecnia, UNESP. E-mail: jandrade@bio.feis.unesp.br 


\title{
SUMMARY: MAIZE GRAIN YIELD IN RESPONSE TO DIFFERENT SOIL MANAGEMENT AND NITROGEN RATES
}

\begin{abstract}
Research has been conducted to identify the best nitrogen (N) rate for maize in most diverse types of soil management. However, there is no agreement on the results, once the dynamic of $N$ is influenced by soil management and cover crops. This study evaluated dry mass production and nutrient uptake by cover crops, agronomic parameters and grain yield of maize in response to soil management and $N$ rates. Field trials were carried out in Selvíria, Mato Grosso do Sul State, Brazil, in the growing seasons of 2009/2010 and 2010 / 2011, on a clayey Rhodic Haplustox ( $20^{\circ} 20^{\prime} \mathrm{S}$ and $51^{\circ} 24^{\prime} \mathrm{W}, 340 \mathrm{~m}$ asl). Thirty-six treatments were established with four replications, in a randomized blocks design, with the combination of cover crops (millet, Crotalaria juncea and millet + Crotalaria juncea), soil management systems (tillage with chisel plow + lightweight disking, heavy disking + lightweight disking, and no-tillage) and topdressing $N$ rates $\left(0,60,90\right.$ e $120 \mathrm{~kg} \mathrm{ha}^{-1}$ - urea as source). Maize hybrid $D K B 350 Y G^{\circledR}$ was used and $N$ applied at stage $V_{5}$ (fifth expanded leaf). A linear increase with the increase of $N$ rates was observed for chlorophyll leaf index, leaf $N$ content, ear length and diameter, and grain weight and yield. Previously grown sunn hemp and millet + sunn hemp grown, associated with $120 \mathrm{~kg} \mathrm{ha}^{-1} \mathrm{~N}$ for maize, induced a higher grain yield after two growing seasons.
\end{abstract}

Index terms: Zea mays, millet, sunn hemp, nitrogen fertilization, yield.

\section{INTRODUÇÃO}

O nitrogênio $(\mathrm{N})$ é o nutriente absorvido em maior quantidade pelo milho e, em razão disso, é altamente responsivo a esse nutriente, apresentando incrementos em várias características que influenciam a produção final (Ohland et al., 2005). A dinâmica do N no sistema solo-planta pode ser influenciada principalmente pelo manejo do solo, tipo de fertilizante, formas de manejo, condições edafoclimáticas (Figueiredo et al., 2005; Santos et al., 2010), coberturas vegetais e população microbiana heterotrófica (Aita \& Giacomini, 2007). Pesquisas comparativas entre sistemas de manejo do solo (plantio direto, cultivo mínimo e sistema convencional) têm evidenciado que a diferença na dinâmica do $\mathrm{N}$ entre esses sistemas é capaz de refletir nas doses a serem aplicadas (Lara Cabezas et al., 2004; Figueiredo et al., 2005; Santos et al., 2010). Figueiredo et al. (2005) avaliaram sistemas de manejo do solo na absorção de $\mathrm{N}$ pelo milho no Cerrado e verificaram que os sistemas de manejo influenciaram a dinâmica de absorção de $\mathrm{N}$ pela planta; entretanto, sob plantio direto e manejo com escarificador, houve maior eficiência de recuperação do $\mathrm{N}$ oriundo do fertilizante. Além disso, os sistemas de manejo do solo influenciam diferentemente a sua densidade, a porosidade e o armazenamento de água ao longo do perfil, interferindo diretamente no desenvolvimento da cultura. Conforme Kluthcouski et al. (2000), a produtividade, na maioria das culturas sob diferentes manejos do solo, apresenta, entretanto, comportamentos variáveis.

$\mathrm{O}$ aumento da dose de $\mathrm{N}$, na maioria das vezes, proporciona incremento na produtividade, porém o aproveitamento de $\mathrm{N}$ decresce com o aumento das doses aplicadas, em vista de o suprimento de $\mathrm{N}$ exceder as necessidades da cultura, na ocasião de sua aplicação. No caso do milho, o aproveitamento raramente ultrapassa $50 \%$ do $\mathrm{N}$ aplicado como fertilizante mineral (Lara Cabezas et al., 2004), em razão de $\mathrm{o} \mathrm{N}$ aplicado no solo estar sujeito às perdas por lixiviação, escorrimento superficial, desnitrificação, volatilização da amônia e pela imobilização na biomassa microbiana (Alva et al., 2006).

$\mathrm{O} \mathrm{N}$ possui papel fundamental no metabolismo vegetal por participar diretamente na biossíntese de proteínas e de clorofilas (Andrade et al., 2003), sendo importante no estádio inicial de desenvolvimento da planta de milho; no entanto, encontra-se em quantidade insuficiente na maioria dos solos brasileiros, tornando-se fundamental o fornecimento dele para obter-se produtividade satisfatória (Belarmino et al., 2003). Além do fornecimento de $\mathrm{N}$ mineral, outra solução para suprir as quantidades insuficientes de $\mathrm{N}$ no solo é o uso de coberturas vegetais. Entre as espécies utilizadas, destacam-se as pertencentes às famílias das fabáceas. Com menor relação $\mathrm{C} / \mathrm{N}$, comparativamente às poáceas, com capacidade de fixação simbiótica do $\mathrm{N}_{2}$, as fabáceas aumentam a disponibilidade de $\mathrm{N}$ no solo, a absorção de $\mathrm{N}$ pela planta e a produtividade de milho (Ohland et al., 2005; Kappes, 2011), podendo contribuir na redução de aplicação de $\mathrm{N}$ mineral. As poáceas contribuem na manutenção de níveis maiores de matéria orgânica no solo, comparadas às fabáceas, por causa da sua alta relação $\mathrm{C} / \mathrm{N}$ e do alto teor de lignina na sua composição, formando húmus de maior estabilidade; porém, podem apresentar problemas em relação à disponibilidade de $\mathrm{N}$.

Uma alternativa que permite aliar as características desejáveis das poáceas e fabáceas é a consorciação entre elas. Quando essa estratégia é adotada, há combinação da maior habilidade das poáceas em ciclar nutrientes com a capacidade das fabáceas em fixar o $\mathrm{N}_{2}$, resultando numa fitomassa 
com relação $\mathrm{C} / \mathrm{N}$ intermediária àquela das culturas exclusivas. Diversas pesquisas relatam o efeito positivo de coberturas vegetais sobre a produtividade do milho (Silva et al., 2006; Carvalho et al., 2007; Sousa Neto et al., 2008); entretanto, vários pesquisadores mencionam a contribuição do $\mathrm{N}$ remanescente dos resíduos culturais (Silva et al., 2006; Strieder et al., 2006; Kappes, 2011).

A utilização de coberturas vegetais, associada à adoção de um sistema que possibilite melhorar as condições do solo e o manejo adequado do N, pode ser de suma importância para o aumento da produtividade do milho. Diante disso, este trabalho objetivou avaliar a produção de matéria seca e o acúmulo de nutrientes em coberturas vegetais, parâmetros produtivos e produtividade do milho em sucessão, sob diferentes manejos do solo e doses de N.

\section{MATERIAL E MÉTODOS}

\section{Descrição da área experimental}

O experimento foi conduzido no município de Selvíria, MS, em área situada a $20^{\circ} 20^{\prime} \mathrm{S}$ e $51^{\circ} 24^{\prime} \mathrm{W}$, com altitude de $340 \mathrm{~m}$. O clima da região, segundo classificação de Köppen, é do tipo Aw, com precipitação pluvial média anual de $1.330 \mathrm{~mm}$, temperatura do ar média anual de $25^{\circ} \mathrm{C}$ e umidade relativa do ar média anual de $66 \%$ (Centurion, 1982). Os experimentos foram conduzidos em condições de campo durante os anos agrícolas 2009/2010 e 2010/2011, em Latossolo Vermelho distrófico textura argilosa (Embrapa, 2006).

\section{Tratamentos e delineamento experimental}

Foram estabelecidos 36 tratamentos com quatro repetições, dispostos em delineamento de blocos ao acaso, que resultaram da combinação dos fatores: cobertura vegetal, manejo do solo e dose de $\mathrm{N}$ em cobertura. As coberturas e os sistemas de manejo do solo foram dispostos em faixas e as doses de $\mathrm{N}$ em cobertura, locadas de maneira casualizadas, dentro das subparcelas definidas pela intersecção das próprias faixas. Como coberturas, utilizaram-se milheto (Pennisetum glaucum L.), crotalária (Crotalaria juncea) e milheto + crotalária. O manejo do solo consistiu em preparo com escarificador + grade "leve" $(\mathrm{E}+\mathrm{GL})$, grade "pesada" + grade "leve" $(\mathrm{GP}+\mathrm{GL})$ e sistema plantio direto (SPD). O manejo com E+GL foi realizado com escarificador de sete hastes na profundidade de trabalho em torno de $0,35 \mathrm{~m}$ e com grade 32 x 20", à profundidade aproximada de $0,1 \mathrm{~m}$. $\mathrm{O}$ manejo com GP+GL foi realizado com grade $14 \mathrm{x}$ 32 " na profundidade em torno de $0,2 \mathrm{~m}$ e com grade $32 \times 20$ " na profundidade de $0,1 \mathrm{~m}$. No SPD, o manejo ficou restrito à desintegração mecânica das coberturas vegetais. As doses de $\mathrm{N}$ foram: 0, 60, 90 e $120 \mathrm{~kg} \mathrm{ha}^{-1}$, utilizando-se como fonte a ureia. As parcelas foram constituídas por seis linhas de milho de $5,0 \mathrm{~m}$ de comprimento, espaçadas de $0,9 \mathrm{~m}$ entre si. Para a coleta dos dados, utilizaram-se as quatro linhas centrais de cada parcela (área útil de $18 \mathrm{~m}^{2}$ ).

\section{Condução do experimento}

A área experimental teve todos os sistemas de manejo do solo instalados no ano agrícola 1997/1998 (Quadro 1). No período de verão de 2008/2009, a área foi cultivada com milho, permanecendo em pousio no inverno seguinte. Antes da instalação dos experimentos, foram realizadas amostragens do solo na camada de 0,0-0,2 m, para análise química (Quadro 2). Previamente à semeadura das coberturas vegetais, as plantas daninhas foram dessecadas com Glifosato (960 e $720 \mathrm{~g} \mathrm{ha}^{-1}$ para os anos agrícolas 2009/2010 e 2010/2011, respectivamente). As plantas de cobertura foram semeadas nos dias 27/08/2009 e 04/10/2010 com semeadora específica para o SPD e mecanismo de distribuição de sementes com fluxo contínuo. O milheto e a crotalária foram semeados em linhas espaçadas de 0,17 e $0,34 \mathrm{~m}$, com quantidades de sementes certificadas de 15 e $50 \mathrm{~kg} \mathrm{ha}^{-1}$, respectivamente. No cultivo consorciado (milheto + crotalária), mantevese a mesma quantidade de sementes utilizada no cultivo exclusivo para ambas as coberturas, intercalando-se as linhas de milheto e de crotalária no espaçamento de $0,17 \mathrm{~m}$. No ano agrícola 2009/2010, a emergência das plântulas ocorreu no quarto e sexto dias após a semeadura (DAS) do milheto (cultivar $\mathrm{ADR}$ $500^{\circledR}$ ) e da crotalária, respectivamente. No ano agrícola 2010/2011, a emergência ocorreu aos seis e cinco DAS do milheto (cultivar BRS- $1501^{\circledR}$ ) e da crotalária, respectivamente.

No ano agrícola 2009/2010, o florescimento das coberturas foi constatado aos 50 DAS, enquanto no de 2010/2011, o florescimento do milheto ocorreu aos 45 DAS e da crotalária, aos 55 DAS, tanto no cultivo exclusivo quanto no consorciado. Não foram realizados adubações e tratamentos fitossanitários nas

\begin{tabular}{ccc}
$\begin{array}{c}\text { Quadro 1. Histórico de exploração agrícola da área } \\
\text { experimental nos três sistemas de } \\
\text { solo estudado }\end{array}$ & & \\
\hline Ano agrícola & Verão & Inverno \\
\hline $1997 / 1998$ & Milho & Pousio \\
$1998 / 1999$ & Milho & Pousio \\
$1999 / 2000$ & Arroz & Feijão \\
$2000 / 2001$ & Arroz & Feijão \\
$2001 / 2002$ & Milho & Feijão \\
$2002 / 2003$ & Milho & Feijão \\
$2003 / 2004$ & Arroz & Trigo \\
$2004 / 2005$ & Arroz & Trigo \\
$2005 / 2006$ & Milho & Pousio \\
$2006 / 2007$ & Milho & Pousio \\
$2007 / 2008$ & Milho & Pousio \\
$2008 / 2009$ & Milho & Pousio \\
\hline
\end{tabular}


Quadro 2. Atributos químicos do solo da área experimental na camada de 0,0-0,2 m nos três sistemas de manejo do solo

\begin{tabular}{|c|c|c|c|c|c|c|c|c|c|}
\hline Manejo do solo ${ }^{(1)}$ & $\mathrm{pH}\left(\mathrm{CaCl}_{2}\right)$ & $\mathbf{P}$ & $\mathbf{K}$ & $\mathbf{C a}$ & $\mathbf{M g}$ & $\mathbf{H}+\mathbf{A l}$ & CTC & $\mathbf{V}$ & MO \\
\hline & & $\mathrm{mg} \mathrm{dm} \mathrm{m}^{-3}$ & \multicolumn{5}{|c|}{$\mathrm{mmol}_{\mathrm{c}} \mathrm{dm}^{-3}$} & $\%$ & $\mathrm{~g} \mathrm{dm} \mathrm{dm}^{-3}$ \\
\hline & & \multicolumn{8}{|c|}{ Ano agrícola 2009/2010 } \\
\hline $\mathrm{E}+\mathrm{GL}$ & 5,5 & 16 & 3,5 & 30 & 17 & 27 & 78 & 65 & 17 \\
\hline $\mathrm{GP}+\mathrm{GL}$ & 5,6 & 12 & 3,1 & 31 & 18 & 30 & 82 & 64 & 19 \\
\hline \multirow[t]{2}{*}{ SPD } & 5,5 & 29 & 2,7 & 31 & 18 & 32 & 84 & 61 & 17 \\
\hline & & \multicolumn{8}{|c|}{ Ano agrícola 2010/2011 } \\
\hline $\mathrm{E}+\mathrm{GL}$ & 5,8 & 28 & 1,8 & 36 & 25 & 20 & 83 & 76 & 20 \\
\hline $\mathrm{GP}+\mathrm{GL}$ & 5,8 & 31 & 1,4 & 32 & 21 & 20 & 74 & 73 & 20 \\
\hline SPD & 5,4 & 26 & 1,7 & 24 & 16 & 25 & 67 & 63 & 18 \\
\hline
\end{tabular}

(1) E+GL: preparo com escarificador + grade "leve"; GP+GL: preparo com grade "pesada" + grade "leve"; e SPD: sistema plantio direto. Extratores: P, K, Ca e Mg (resina); H+Al (tampão SMP); MO (fotométrico); CTC e V: cálculo.

coberturas. O fornecimento de água foi feito com sistema de irrigação por aspersão do tipo "canhão" hidráulico autopropelido, levando-se em consideração os dados de precipitação pluvial registrados. No ano agrícola 2009/2010, as coberturas foram dessecadas com Glifosato (1.440 $\left.\mathrm{g} \mathrm{ha}^{-1}\right)$ e 2,4-D sal dimetilamina (800 $\left.\mathrm{g} \mathrm{ha}^{-1}\right)$, aos 63 DAS. No ano agrícola 2010/2011, as coberturas foram dessecadas aos 56 DAS com Glifosato (1.920 $\mathrm{g} \mathrm{ha}^{-1}$ ) e 2,4-D sal dimetilamina (400 $\left.\mathrm{g} \mathrm{ha}^{-1}\right)$. Respectivamente aos cinco e sete dias após a dessecação para os anos agrícolas 2009/2010 e $2010 / 2011$, as coberturas foram manejadas com desintegrador mecânico horizontal (Triton), com altura de corte de $15 \mathrm{~cm}$. Após o manejo das coberturas no primeiro ano de cultivo, aplicou-se 1,5 tha $^{-1}$ de calcário $(\mathrm{PRNT}=85 \% ; \mathrm{CaO}=36$ a $39 \% ; \mathrm{e} \mathrm{MgO}=12$ a $15 \%)$, com distribuição a lanço em área total.

O solo foi manejado logo após a coleta do material para determinação da massa de matéria seca da parte aérea das plantas de cobertura. Na semeadura do milho, o híbrido utilizado foi o DKB 350 YG (Dekalb ${ }^{\circledR}$ ), tipo triplo, ciclo precoce (860 graus dia) e grãos duros alaranjados. Em ambos os anos de cultivo, as sementes foram tratadas com os inseticidas Imidacloprido e Tiodicarbe nas doses de 50 e 155 g para 60.000 sementes, respectivamente. As semeaduras do milho foram realizadas nos dias 16/11/2009 e 11/12/2010 e a emergência das plântulas ocorreu aos seis DAS nos três sistemas de manejo do solo, estabelecendo-se população inicial de 54.490 e 54.430 plantas ha ${ }^{-1}$, respectivamente para os anos agrícolas 2009/2010 e 2010/2011. Utilizou-se semeadora específica para o SPD, equipada com mecanismo sulcador de hastes (tipo "botinha") e sistema de distribuição de sementes pneumático.

$\mathrm{Na}$ adubação mineral de semeadura, foram aplicados $300 \mathrm{~kg} \mathrm{ha}^{-1}$ da fórmula NPK 08-28-16. As plantas daninhas foram manejadas, em ambos os anos de cultivo, com os herbicidas Atrazina $\left(1.000 \mathrm{~g} \mathrm{ha}^{-1}\right) \mathrm{e}$ Tembotriona ( $\left.100 \mathrm{~g} \mathrm{ha}^{-1}\right)$ e o adjuvante éster metilado de óleo de soja $\left(720 \mathrm{~g} \mathrm{ha}^{-1}\right)$. Na ocasião das aplicações, as plantas daninhas estavam nos estádios iniciais de desenvolvimento e a cultura nos estádios $\mathrm{V}_{6}$ (sexta folha expandida) $\mathrm{e}_{5}$ (quinta folha expandida)(Ritchie et al., 2003) nos anos agrícolas 2009/2010 e 2010/2011, respectivamente. Não houve a necessidade de manejo químico da lagarta-do-cartucho (Spodoptera frugiperda) nos dois anos de cultivo.

$\mathrm{O} \mathrm{N}$ foi aplicado quando as plantas apresentavamse no estádio $V_{5}$ (Ritchie et al., 2003). As aplicações foram realizadas sobre a superfície do solo (sem incorporação), aproximadamente $5,0 \mathrm{~cm}$ ao lado das plantas, em forma de faixas/filetes. No momento das aplicações do N, o solo apresentava-se com boas condições de umidade. O florescimento da cultura, estádio $R_{1}$ (Ritchie et al., 2003), ocorreu aos 56 DAS, em ambos os anos de cultivo.

\section{Variáveis analisadas}

\section{Plantas de cobertura}

Na ocasião do manejo das plantas de cobertura, foi avaliada a massa de matéria seca da parte aérea (MSPA). Foram realizadas amostragens ao acaso com quadrante de $0,25 \mathrm{~m}^{2} \mathrm{em}$ dois pontos representativos de cada parcela. Em seguida, o material foi submetido à secagem em estufa com renovação e circulação forçada de ar à temperatura de $65 \pm 5^{\circ} \mathrm{C}$, até atingir massa constante. A produção de MSPA foi obtida pela média aritmética entre os dois pontos amostrados, com os valores extrapolados para $\mathrm{kg} \mathrm{ha}^{-1}$. Posteriormente, determinaram-se o teor de N, P e K nas amostras, conforme descrito por Malavolta et al. (1997). Pelo produto do teor dos nutrientes $\left(\mathrm{g} \mathrm{kg}^{-1}\right)$ com a produção de MSPA ( $\mathrm{kg} \mathrm{ha}^{-1}$ ), obteve-se o N, P e K acumulado pelas plantas de cobertura $\left(\mathrm{kg} \mathrm{ha}^{-1}\right)$.

\section{Milho}

Em razão de o $\mathrm{N}$ participar diretamente na biossíntese de proteínas e de clorofilas (Andrade et al., 
2003), durante o desenvolvimento da cultura, foi realizada a estimativa do teor de clorofila foliar com a utilização do clorofilômetro portátil ClorofiLOG ${ }^{\circledR}$ (modelo CFL 1030), que, por meio de sensores, analisa as relações de absorção de faixas de frequências, fornecendo medições dos teores das clorofilas $a, b$ e total $(a+b)$, expressas em unidades dimensionais chamadas ICF (Indice de Clorofila Foliar). Realizaramse as leituras em três épocas (Ritchie et al., 2003): no estádio $\mathrm{V}_{5}$ (ocasião da aplicação do $\mathrm{N}$ ), no estádio $\mathrm{V}_{10}$ ( $10^{\mathrm{a}}$ folha expandida) e no florescimento. As duas primeiras leituras foram efetuadas na porção central da última folha recentemente desenvolvida (fora do "cartucho") e na folha oposta e abaixo da espiga principal, para a terceira leitura. Foram consideradas aleatoriamente três plantas por parcela. Simultaneamente ao registro da terceira leitura do ICF, coletaram-se os terços centrais de 10 folhas situadas opostamente e abaixo da espiga principal para determinação do teor de N (Malavolta et al., 1997).

No estádio $R_{3}$ (grão pastoso) (Ritchie et al., 2003), o diâmetro de colmo - DC (segundo internódio a partir da base da planta) foi medido. As colheitas (duas linhas centrais) foram realizadas nos dias 08/04/2010 (143 DAS) e 21/04/2011 (131 DAS), sendo avaliados em 10 espigas por parcela: comprimento de espiga - CE, diâmetro de espiga - DE (porção mediana) e número de fileiras de grãos por espiga - NFG. Após a trilha mecânica das espigas, mensurou-se a massa de 1.000 grãos - MMG (pesagem de uma subamostra de 250 grãos por parcela em balança de precisão, extrapolando-se o valor para 1.000 grãos com a massa corrigida para $13 \%$ de umidade - b.u.) e produtividade (pesagem dos grãos oriundos das espigas colhidas na área útil das parcelas, extrapolação para $\mathrm{kg} \mathrm{ha}^{-1} \mathrm{e}$ correção da massa para $13 \%$ de umidade - b.u.).

\section{Análises estatísticas}

Os resultados foram submetidos ao teste $\mathrm{F}$, comparando-se as médias de cobertura vegetal e sistema de manejo do solo pelo teste de Tukey a $5 \%$. As médias de dose de $\mathrm{N}$ foram submetidas à análise de regressão, ajustando-se modelos de equações significativas pelo teste $\mathrm{F}$.

\section{RESULTADOS E DISCUSSÃO}

\section{Plantas de cobertura}

A quantidade de MSPA acumulada pela crotalária e pelo consórcio milheto + crotalária foi maior comparativamente ao milheto, em ambos os anos agrícolas (Quadro 3). Apesar da menor MSPA do milheto, seus resíduos promoveram cobertura mais persistente do solo quando comparada à da crotalária, o que está relacionado à sua maior relação $\mathrm{C} / \mathrm{N}$ (Alva et al., 2006), em relação às fabáceas. Silva et al. (2006) estudaram o manejo do $\mathrm{N}$ no milho em SPD sob diferentes coberturas vegetais e também obtiveram maior MSPA da Crotalaria juncea, em comparação ao milheto. Entretanto, Francisco et al. (2011), avaliando coberturas vegetais antecedendo o cultivo do milho no Cerrado, obtiveram maior quantidade de MSPA com o milheto, em relação à crotalária $(C$. ochroleuca). O manejo do solo realizado com GP+GL e SPD proporcionou maior produção de MSPA das plantas de cobertura, no segundo ano de cultivo. A crotalária e o milheto + crotalária proporcionaram maior quantidade de $\mathrm{N}$ e $\mathrm{P}$ acumulada na MSPA, em ambos os anos de cultivo (Quadro 3). O maior teor de $\mathrm{N}$ acumulado na MSPA foi encontrado na crotalária, por tratar-se de uma fabácea capaz de fixar biologicamente $\mathrm{N}_{2}$ (Ohland et al., 2005; Kappes, 2011) e de reciclar $\mathrm{N}$ das camadas mais profundas do solo. $\mathrm{O}$ manejo do solo não interferiu no acúmulo de $\mathrm{N}, \mathrm{Pe}$ K na MSPA no ano agrícola 2009/2010. Porém, o SPD, no ano agrícola 2010/2011, favoreceu maior acúmulo desses nutrientes na MSPA das plantas de cobertura, embora essa superioridade não tenha diferido estatisticamente do manejo do solo com GP+GL.

\section{Milho}

No ano agrícola 2009/2010, o cultivo de crotalária e de milheto + crotalária resultou em maior ICF em plantas de milho no estádio $\mathrm{V}_{5}$ (Quadro 4). Tal resultado confirmou os principais benefícios da crotalária para a agricultura: fixação biológica do $\mathrm{N}_{2}$, aumento da disponibilidade de $\mathrm{N}$ no solo e absorção de $\mathrm{N}$ pela planta (Ohland et al., 2005; Kappes, 2011). Contudo, em ambos os anos agrícolas, o ICF em plantas de milho no estádio $V_{10}$ não foi influenciado pelas coberturas vegetais. O SPD promoveu maior ICF em plantas no estádio $\mathrm{V}_{5}$, no ano agrícola $2009 / 2010$, embora não tenha se diferenciado do manejo do solo com E+GL. Maiores ICF em plantas no estádio $\mathrm{V}_{10} \mathrm{e}$ florescimento foram obtidos quando o solo foi manejado com E+GL e GP+GL, respectivamente, nos anos agrícolas 2010/2011 e 2009/2010, o que está relacionado à rápida mineralização dos resíduos culturais e disponibilização de $\mathrm{N}$ favorecida pelo revolvimento do solo em relação ao SPD, ratificando a constatação do estudo de Lara Cabezas et al. (2004). No SPD, podem ter ocorrido perdas de $\mathrm{N}$ em razão da imobilização na biomassa microbiana (Alva et al., 2006), ocasionando menor ICF. No estádio $\mathrm{V}_{10}$, em ambos os anos de cultivo, o incremento nas doses de $\mathrm{N}$ propiciou aumento linear do ICF, resposta que pode ser atribuída à própria função do nutriente, como participação direta na biossíntese de proteínas e de clorofilas (Andrade et al., 2003). Aumento do ICF em função de doses de $\mathrm{N}$ em cobertura no milho também foi observado por Argenta et al. (2003).

$\mathrm{Na}$ ausência de $\mathrm{N}$ em cobertura em ambos os anos agrícolas, o cultivo de crotalária e de milheto + crotalária resultou em maior ICF no florescimento (Quadro 6), demonstrando novamente, os efeitos benéficos da crotalária (Ohland et al., 2005; Kappes, 2011). Na aplicação de $90 \mathrm{~kg} \mathrm{ha}^{-1}$ de N, no ano agrícola 
Quadro 3. Valores médios e resumo da análise de variância de produção de massa de matéria seca de parte aérea (MSPA) e de N, P e K acumulados na MSPA das coberturas vegetais, sob diferentes sistemas de manejo do solo

\begin{tabular}{|c|c|c|c|c|c|c|c|c|c|}
\hline \multirow{2}{*}{\multicolumn{2}{|c|}{ Tratamento }} & \multicolumn{2}{|c|}{ MSPA } & \multicolumn{2}{|c|}{$\mathbf{N}$ acumulado } & \multicolumn{2}{|c|}{$P$ acumulado } & \multicolumn{2}{|c|}{ K acumulado } \\
\hline & & $2009 / 2010$ & 2010/2011 & 2009/2010 & 2010/2011 & 2009/2010 & 2010/2011 & 2009/2010 & 2010/2011 \\
\hline \multirow{2}{*}{\multicolumn{10}{|c|}{ Cobertura vegetal (C) }} \\
\hline & & & & & & & & & \\
\hline Milheto & & $7.765 \mathrm{~b}$ & $9.323 \mathrm{~b}$ & $64,2 \mathrm{~b}$ & $84,4 \mathrm{~b}$ & $18,3 \mathrm{~b}$ & $17,6 \mathrm{~b}$ & 156,1 & 204,1 \\
\hline Crotalária & & $10.047 \mathrm{a}$ & $14.377 \mathrm{a}$ & $142,1 \mathrm{a}$ & $219,5 \mathrm{a}$ & $24,9 \mathrm{a}$ & 35,0 a & 146,6 & 265,1 \\
\hline Milheto + & otalária & $9.880 \mathrm{a}$ & $12.554 \mathrm{a}$ & $132,4 \mathrm{a}$ & $188,1 \mathrm{a}$ & $26,2 \mathrm{a}$ & $32,7 \mathrm{a}$ & 173,0 & 279,8 \\
\hline \multicolumn{10}{|c|}{ Manejo do solo $(\mathrm{M})^{(1)}$} \\
\hline E+GL & & 8.814 & $10.730 \mathrm{~b}$ & 105,9 & $131,8 \mathrm{~b}$ & 22,3 & $23,4 \mathrm{~b}$ & 150,5 & $203,8 \mathrm{~b}$ \\
\hline $\mathrm{GP}+\mathrm{GL}$ & & 9.063 & $12.874 \mathrm{a}$ & 115,8 & $176,5 \mathrm{ab}$ & 23,5 & $30,8 \mathrm{a}$ & 161,2 & $264,6 \mathrm{ab}$ \\
\hline SPD & & 9.814 & $12.650 \mathrm{a}$ & 117,0 & 183,6 a & 23,6 & $31,1 \mathrm{a}$ & 164,0 & 280,7 a \\
\hline \multirow[t]{3}{*}{ Valor $\mathrm{F}^{(2)}$} & $\mathrm{C}$ & $14,84 * *$ & $14,51 * *$ & $35,12 * *$ & $19,35 * *$ & $10,94 * *$ & $17,14 * *$ & 2,65 & 4,13 \\
\hline & M & 1,08 & $10,00 * *$ & 0,43 & $6,49 *$ & 0,16 & $13,13 * *$ & 0,43 & $5,30 *$ \\
\hline & $\mathrm{C} \times \mathrm{M}$ & 1,46 & 2,07 & 0,97 & 2,67 & 0,60 & 0,31 & 1,73 & 0,11 \\
\hline CV (\%) & & 9,57 & 8,83 & 17,88 & 11,21 & 16,18 & 14,78 & 17,84 & 14,13 \\
\hline
\end{tabular}

(1) E+GL: preparo com escarificador + grade "leve"; GP+GL: preparo com grade "pesada" + grade "leve"; SPD: sistema plantio direto. ${ }^{(2)}$ Teste $\mathrm{F}: * * \mathrm{e} *$ : significativo a 1 e $5 \%$, respectivamente. Médias seguidas por mesma letra nas colunas não diferem pelo teste de Tukey a $5 \%$. CV: coeficiente de variação.

Quadro 4. Valores médios e resumo da análise de variância de índice de clorofila foliar em plantas de milho no estádio $V_{5}$ (quinta folha expandida), $V_{10}$ (décima folha expandida) e florescimento e teor de $\mathrm{N}$ foliar no florescimento e diâmetro de colmo (DC) no estádio $R_{3}$ (grão pastoso) em função de coberturas vegetais, sistemas de manejo do solo e doses de $\mathrm{N}$ em cobertura

\begin{tabular}{|c|c|c|c|c|c|c|c|c|c|c|c|}
\hline \multirow{2}{*}{ Tratamento } & & \multicolumn{6}{|c|}{ Índice de clorofila foliar } & \multirow{2}{*}{\multicolumn{2}{|c|}{ Teor de N foliar }} & \multirow{2}{*}{\multicolumn{2}{|c|}{ DC }} \\
\hline & & \multicolumn{2}{|c|}{ Estádio $_{5}$} & \multicolumn{2}{|c|}{ Estádio $V_{10}$} & \multicolumn{2}{|c|}{ Florescimento } & & & & \\
\hline & & & & & & & & $\longrightarrow \mathrm{g} \mathbf{l}$ & $\mathbf{g}^{-1}$ & $\longrightarrow \mathbf{m}$ & $\mathbf{m}$ \\
\hline & & 2009/2010 & 2010/2011 & 2009/2010 & 2010/2011 & 2009/2010 & 2010/2011 & 2009/2010 & 2010/2011 & $2009 / 2010$ & 2010/2011 \\
\hline \multicolumn{12}{|c|}{ Cobertura vegetal (C) } \\
\hline \multicolumn{2}{|l|}{ Milheto } & $36,1 \mathrm{~b}$ & 39,7 & 41,6 & 52,4 & 59,9 & 53,0 & 23,9 & 21,5 & 22,4 & 24,0 \\
\hline \multicolumn{2}{|l|}{ Crotalária } & $39,2 \mathrm{a}$ & 40,1 & 42,8 & 53,8 & 64,6 & 60,2 & 26,3 & 25,3 & 23,3 & 24,3 \\
\hline \multicolumn{2}{|c|}{ Milheto + crotalária } & $38,4 \mathrm{a}$ & 40,7 & 43,3 & 52,9 & 66,4 & 60,1 & 26,2 & 24,9 & 23,3 & 24,4 \\
\hline \multicolumn{12}{|c|}{ Manejo do solo $(\mathrm{M})^{(1)}$} \\
\hline \multicolumn{2}{|l|}{$\mathrm{E}+\mathrm{GL}$} & $38,0 \mathrm{ab}$ & 39,9 & 42,3 & $53,9 \mathrm{a}$ & $66,6 \mathrm{a}$ & 58,0 & $26,4 \mathrm{a}$ & 24,1 & $23,2 \mathrm{a}$ & 24,5 \\
\hline \multicolumn{2}{|c|}{$\mathrm{GP}+\mathrm{GL}$} & $36,7 \mathrm{~b}$ & 39,9 & 43,1 & $53,8 \mathrm{a}$ & $66,3 \mathrm{a}$ & 59,3 & $26,2 \mathrm{a}$ & 24,4 & $23,4 \mathrm{a}$ & 24,2 \\
\hline \multicolumn{2}{|l|}{ SPD } & $39,0 \mathrm{a}$ & 40,6 & 42,3 & $51,3 \mathrm{~b}$ & $58,0 \mathrm{~b}$ & 55,9 & $23,7 \mathrm{~b}$ & 23,2 & $22,3 \mathrm{~b}$ & 24,0 \\
\hline \multicolumn{12}{|c|}{ Dose de N (D) $\left(\mathrm{kg} \mathrm{ha}^{-1}\right)$} \\
\hline \multicolumn{2}{|c|}{0} & - & - & $40,0^{(3)}$ & $51,3^{(4)}$ & 56,2 & 51,1 & 22,2 & 20,6 & $21,5^{(5)}$ & $22,8^{(6)}$ \\
\hline \multicolumn{2}{|l|}{60} & - & - & 43,2 & 52,7 & 65,1 & 57,5 & 25,9 & 24,1 & 23,4 & 24,1 \\
\hline \multicolumn{2}{|l|}{90} & - & - & 43,2 & 53,5 & 64,9 & 60,3 & 26,5 & 25,2 & 23,3 & 25,3 \\
\hline \multicolumn{2}{|l|}{120} & - & - & 44,0 & 54,6 & 68,5 & 62,1 & 27,2 & 25,9 & 23,8 & 24,7 \\
\hline \multirow{7}{*}{ Valor $\mathrm{F}^{(2)}$} & $\mathrm{C}$ & $14,01^{* *}$ & 0,16 & 2,46 & 2,37 & $17,96^{* *}$ & $13,49^{* * *}$ & $6,29 *$ & $81,29 * *$ & 4,76 & 0,24 \\
\hline & M & $12,50^{* *}$ & 0,27 & 1,19 & $11,15^{* *}$ & $14,42^{* *}$ & 3,56 & $17,10^{* * *}$ & $8,06^{*}$ & $74,56^{* * *}$ & 1,29 \\
\hline & $\mathrm{D}$ & - & - & $8,40 * *$ & $4,74^{* *}$ & $34,46^{* *}$ & $24,39^{* *}$ & $67,95^{* *}$ & $61,60^{* *}$ & $30,26^{* *}$ & $33,84^{* *}$ \\
\hline & $\mathrm{C} \times \mathrm{M}$ & $1,15^{* *}$ & 1,60 & 0,14 & 0,85 & $1,13^{*}$ & 1,46 & 1,64 & 1,75 & 0,21 & 0,06 \\
\hline & $\mathrm{C} \times \mathrm{D}$ & - & - & 1,29 & 0,26 & $2,35^{* *}$ & $7,83^{* *}$ & $3,26 * *$ & $16,10^{* *}$ & 1,98 & 0,58 \\
\hline & $\mathrm{M} \times \mathrm{D}$ & - & - & 0,28 & 1,81 & $0,71^{*}$ & 1,42 & 0,60 & $4,01^{* *}$ & 0,87 & 0,45 \\
\hline & $\mathrm{C} \times \mathrm{M} \times \mathrm{D}$ & - & - & 0,69 & 1,43 & $0,85^{*}$ & 1,57 & 0,38 & 1,66 & 0,58 & 0,57 \\
\hline \multicolumn{2}{|l|}{ CV (\%) } & 5,12 & 7,19 & 7,32 & 6,29 & 9,24 & 7,25 & 7,33 & 5,39 & 4,96 & 5,69 \\
\hline
\end{tabular}

(1) E+GL: preparo com escarificador + grade "leve"; GP+GL: preparo com grade "pesada" + grade "leve"; SPD: sistema plantio direto. ${ }^{(2)}$ Teste F: ** e *: significativo a 1 e $5 \%$, respectivamente. ${ }^{(3)} \hat{y}=40,389+0,033 x^{* *}, R^{2}=0,89 .{ }^{(4)} \hat{y}=51,206+0,027 x^{* *}, R^{2}$ $=0,99 .{ }^{(5)} \hat{y}=21,726+0,019 x^{* *}, R^{2}=0,87 .{ }^{(6)} \hat{y}=22,971+0,019 x^{* *}, R^{2}=0,79$. Médias seguidas por mesma letra nas colunas não diferem pelo teste de Tukey a $5 \%$. CV: coeficiente de variação. 
2010/2011, obteve-se maior ICF no florescimento do milho quando o milheto + crotalária antecederam o milho, apesar de não ter sido verificada diferença em relação ao cultivo da crotalária exclusiva, evidenciando o efeito positivo dessa em relação ao milheto exclusivo. Entretanto, quando aplicados $120 \mathrm{~kg} \mathrm{ha}^{-1}$ de N, em ambos os anos de cultivo, o efeito positivo da crotalária não foi evidente em comparação ao milheto, indicando que tal dose foi suficiente em suprir $\mathrm{N}$ ao milho, apesar da alta relação $\mathrm{C} / \mathrm{N}$ do milheto (Alva et al., 2006). O ICF no florescimento aumentou linearmente com a elevação nas doses de $\mathrm{N}$ após as coberturas vegetais nos dois anos de cultivo, fato creditado à participação direta do $\mathrm{N}$ na biossíntese de proteínas e de clorofilas (Andrade et al., 2003).

De maneira similar à constatada para o ICF no florescimento no ano agrícola 2009/2010, o manejo do solo com E+GL e GP+GL propiciou maior teor de N foliar (Quadro 4), o que está relacionado à rápida mineralização dos resíduos culturais e disponibilização de $\mathrm{N}$ favorecida pelo revolvimento do solo, em relação ao SPD. Tal resultado apontou para o fato de que, no SPD, comparado aos manejos com revolvimento do solo, há necessidade de aumento nas doses de $\mathrm{N}$ para que o milho apresente maiores teores desse nutriente nas folhas, em razão das modificações na dinâmica do $\mathrm{N}$ nesse sistema, como a lenta taxa de decomposição dos resíduos vegetais deixados na superfície do solo e maior taxa de imobilização microbiana.

Quando não se aplicou N em cobertura, em ambos os anos agrícolas, o cultivo de crotalária e de milheto + crotalária proporcionou maior teor de $\mathrm{N}$ foliar (Quadro 6), resposta atribuída às maiores quantidades de $\mathrm{N}$ acumuladas na MSPA dessas plantas de cobertura (Quadro 3) e consequentemente à maior disponibilidade de $\mathrm{N}$ ao milho. No ano agrícola 2010/ 2011, a utilização de crotalária e de milheto + crotalária resultou em maiores teores de $\mathrm{N}$ foliar, quando aplicados 60 e $90 \mathrm{~kg} \mathrm{ha}^{-1} \mathrm{de} \mathrm{N}$. Em ambos os anos de cultivo, o teor de $\mathrm{N}$ foliar aumentou linearmente com o incremento nas doses de $\mathrm{N}$ após as coberturas vegetais. O manejo do solo com GP+GL favoreceu maior teor de $\mathrm{N}$ foliar, quando aplicado $90 \mathrm{~kg} \mathrm{ha}^{-1}$ de N no ano agrícola 2010/2011 (Quadro 8), embora não se tenha constatado diferença em comparação ao manejo com $\mathrm{E}+\mathrm{GL}$, pois o revolvimento do solo favoreceu a rápida mineralização dos resíduos culturais e disponibilização de $\mathrm{N}$, com consequente

Quadro 5. Valores médios e resumo da análise de variância de comprimento de espiga (CE), do diâmetro de espiga (DE), do número de fileiras de grãos por espiga (NFG), da massa de 1.000 grãos (MMG) e da produtividade (PROD) de milho em razão de coberturas vegetais, sistemas de manejo do solo e doses de N em cobertura

\begin{tabular}{|c|c|c|c|c|c|c|c|c|c|c|c|}
\hline \multirow{2}{*}{\multicolumn{2}{|c|}{ Tratamento }} & \multicolumn{2}{|c|}{$\mathbf{C E}$} & \multicolumn{2}{|c|}{ DE } & \multicolumn{2}{|c|}{ NFG } & \multicolumn{2}{|c|}{ MMG } & \multicolumn{2}{|c|}{ PROD } \\
\hline & & 2009/2010 & 2010/2011 & 2009/2010 & 2010/2011 & 2009/2010 & 2010/2011 & 2009/2010 & 2010/2011 & 2009/2010 & 2010/2011 \\
\hline & & 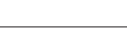 & $\mathbf{n}$ & $\mathbf{n}$ & - & 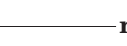 & $\mathbf{n}^{\mathbf{o}}$ & $\longrightarrow$ & & kg & $1 \mathbf{a}^{-1}$ \\
\hline \multicolumn{12}{|c|}{ Cobertura vegetal (C) } \\
\hline \multicolumn{2}{|l|}{ Milheto } & $152,8 \mathrm{~b}$ & 160,1 & 45,6 & 47,7 & 14,9 & 14,8 & 279,1 & 281,2 & 5.534 & 6.847 \\
\hline \multicolumn{2}{|c|}{ Crotalária } & $159,2 \mathrm{a}$ & 164,0 & 45,8 & 48,0 & 14,8 & 15,0 & 294,5 & 295,1 & 6.434 & 7.968 \\
\hline \multicolumn{2}{|c|}{ Milheto + crotalária } & $156,4 \mathrm{a}$ & 164,0 & 46,1 & 48,3 & 15,0 & 14,9 & 294,6 & 297,7 & 6.308 & 7.807 \\
\hline \multicolumn{12}{|c|}{ Manejo do solo $(\mathrm{M})^{(1)}$} \\
\hline \multicolumn{2}{|l|}{ E+GL } & $160,1 \mathrm{a}$ & 162,8 & 45,9 & 48,0 & 14,9 & 15,0 & 291,3 & 289,2 & 6.087 & 7.326 \\
\hline \multicolumn{2}{|l|}{$\mathrm{GP}+\mathrm{GL}$} & $157,7 \mathrm{a}$ & 161,7 & 46,0 & 47,9 & 14,9 & 14,9 & 289,9 & 286,3 & 6.002 & 7.538 \\
\hline \multicolumn{2}{|l|}{ SPD } & $150,7 \mathrm{~b}$ & 163,5 & 45,5 & 48,1 & 14,9 & 14,9 & 286,8 & 298,5 & 6.187 & 7.758 \\
\hline \multicolumn{12}{|c|}{ Dose de N (D) $\left(\mathrm{kg} \mathrm{ha}^{-1}\right)$} \\
\hline \multicolumn{2}{|c|}{0} & $148,3^{(3)}$ & 156,0 & $45,3^{(4)}$ & $47,2^{(5)}$ & 14,9 & 14,8 & 281,6 & 285,8 & 5.359 & 6.492 \\
\hline \multicolumn{2}{|l|}{60} & 155,7 & 163,5 & 45,9 & 48,2 & 14,9 & 14,9 & 288,4 & 291,1 & 6.156 & 7.506 \\
\hline \multicolumn{2}{|l|}{90} & 159,4 & 164,6 & 46,1 & 48,2 & 15,0 & 14,9 & 292,7 & 293,8 & 6.299 & 7.889 \\
\hline \multicolumn{2}{|l|}{120} & 161,2 & 166,7 & 45,9 & 48,4 & 14,8 & 15,0 & 294,8 & 294,7 & 6.554 & 8.275 \\
\hline \multirow{7}{*}{ Valor $\mathrm{F}^{(2)}$} & $\mathrm{C}$ & $7,89^{*}$ & $9,40 *$ & 2,88 & 4,16 & 2,96 & 2,58 & $25,99 * *$ & $21,31 * *$ & $24,22 * *$ & $12,38 * *$ \\
\hline & M & $28,91^{* *}$ & 0,84 & 3,01 & 1,97 & 0,21 & 1,48 & 0,85 & $37,94 * *$ & 0,39 & 2,02 \\
\hline & $\mathrm{D}$ & $41,93^{* *}$ & $18,90 * *$ & $17,77 * *$ & $6,10 * *$ & 0,41 & 1,12 & $14,79 * *$ & $6,17 * *$ & $24,80 * *$ & $30,13 * *$ \\
\hline & $\mathrm{C} \times \mathrm{M}$ & 0,89 & 1,33 & 0,46 & 0,49 & 0,66 & 0,51 & 0,34 & $3,84 * *$ & 1,77 & $4,17 * *$ \\
\hline & $\mathrm{C} \times \mathrm{D}$ & 1,90 & $3,07 * *$ & 0,58 & 1,28 & 1,24 & 0,95 & $4,17 * *$ & $5,08^{* *}$ & $4,54 * *$ & $5,41 * *$ \\
\hline & $M \times D$ & 0,76 & $3,77 * *$ & 1,30 & 0,73 & 0,28 & 2,18 & 0,38 & 2,02 & 1,26 & 2,23 \\
\hline & $C \times M \times D$ & 0,90 & 1,09 & 0,76 & 0,93 & 0,58 & 1,68 & 0,74 & 0,56 & 1,34 & 0,92 \\
\hline \multicolumn{2}{|l|}{$\mathrm{CV}(\%)$} & 3,82 & 3,56 & 2,25 & 1,89 & 3,84 & 3,08 & 2,98 & 3,12 & 8,02 & 7,63 \\
\hline
\end{tabular}

1) E+GL: preparo com escarificador + grade "leve"; GP+GL: preparo com grade "pesada" + grade "leve"; SPD: sistema plantio direto. ${ }^{(2)}$ Teste $\mathrm{F}: * * \mathrm{e}^{*}$ : significativo a 1 e $5 \%$, respectivamente. ${ }^{(3)} \hat{\mathrm{y}}=148,680+0,111 \mathrm{x}^{* *}, \mathrm{R}^{2}=0,98 .{ }^{(4)} \hat{\mathrm{y}}=45,414+0,006 \mathrm{x}^{* *}$, $\mathrm{R}^{2}=0,71$. $^{(5)} \hat{\mathrm{y}}=47,331+0,009 \mathrm{x}^{* *}, \mathrm{R}^{2}=0,88$. Médias seguidas por mesma letra nas colunas não diferem pelo teste de Tukey a $5 \%$. CV: coeficiente de variação. 
Quadro 6. Índice de clorofila foliar (ICF) e teor de $\mathrm{N}$ foliar no florescimento, no comprimento de espiga, no número de fileiras de grãos por espiga, na massa de 1.000 grãos e na produtividade do milho em razão de coberturas vegetais e doses de $\mathbf{N}$ em cobertura

\begin{tabular}{|c|c|c|c|c|c|c|}
\hline \multirow{2}{*}{ Cobertura vegetal } & \multicolumn{4}{|c|}{ Dose de N (kg ha $\left.{ }^{-1}\right)$} & \multirow{2}{*}{ Equação de regressão } & \multirow{2}{*}{$\mathbf{R}^{2}$} \\
\hline & $\mathbf{0}$ & 60 & 90 & 120 & & \\
\hline \multicolumn{7}{|c|}{ ICF no florescimento $(2009 / 2010)$} \\
\hline Milheto & $48,9 \mathrm{~b}$ & 63,0 a & 60,9 a & 66,8 a & $\hat{y}=50,437+0,141 x^{* *}$ & 0,86 \\
\hline Crotalária & $60,5 \mathrm{a}$ & $63,6 \mathrm{a}$ & $66,2 \mathrm{a}$ & $68,2 \mathrm{a}$ & $\hat{\mathrm{y}}=60,261+0,065 \mathrm{x}^{* *}$ & 0,99 \\
\hline $\mathrm{M}+\mathrm{C}$ & $59,3 \mathrm{a}$ & 68,6 a & $67,4 \mathrm{a}$ & $70,3 \mathrm{a}$ & $\hat{y}=60,486+0,088 x^{* *}$ & 0,85 \\
\hline \multicolumn{7}{|c|}{ ICF no florescimento $(2010 / 2011)$} \\
\hline Milheto & $40,9 \mathrm{~b}$ & $54,4 \mathrm{a}$ & $56,3 \mathrm{~b}$ & $60,5 \mathrm{a}$ & $\hat{\mathrm{y}}=42,103+0,162 \mathrm{x}^{* *}$ & 0,96 \\
\hline Crotalária & 56,8 a & 59,4 a & $61,2 \mathrm{ab}$ & $63,2 \mathrm{a}$ & $\hat{\mathrm{y}}=56,589+0,053 \mathrm{x}^{* *}$ & 0,99 \\
\hline $\mathrm{M}+\mathrm{C}$ & 55,7 a & 58,6 a & 63,4 a & 62,6 a & $\hat{\mathrm{y}}=55,671+0,065 \mathrm{x}^{* *}$ & 0,86 \\
\hline \multicolumn{7}{|c|}{ Teor de $\mathrm{N}$ foliar $\left(\mathrm{g} \mathrm{kg}^{-1}\right)(2009 / 2010)$} \\
\hline Milheto & $19,0 \mathrm{~b}$ & 24,7 a & $25,3 \mathrm{a}$ & $26,5 \mathrm{a}$ & $\hat{y}=19,651+0,063 x^{* *}$ & 0,92 \\
\hline Crotalária & $23,8 \mathrm{a}$ & 26,5 a & $27,1 \mathrm{a}$ & $27,7 \mathrm{a}$ & $\hat{\mathrm{y}}=24,057+0,033 \mathrm{x}^{* *}$ & 0,96 \\
\hline $\mathrm{M}+\mathrm{C}$ & 23,7 a & 26,6 a & 27,1 a & $27,3 \mathrm{a}$ & $\hat{y}=24,086+0,031 x^{* *}$ & 0,89 \\
\hline \multicolumn{7}{|c|}{ Teor de $\mathrm{N}$ foliar $\left(\mathrm{g} \mathrm{kg}^{-1}\right)(2010 / 2011)$} \\
\hline Milheto & $15,9 \mathrm{~b}$ & $21,6 \mathrm{~b}$ & $23,7 \mathrm{~b}$ & $25,0 \mathrm{a}$ & $\hat{y}=16,317+0,077 x^{* *}$ & 0,98 \\
\hline Crotalária & 23,6 a & 25,5 a & 25,6 a & 26,5 a & $\hat{\mathrm{y}}=23,731+0,023 \mathrm{x}^{* *}$ & 0,95 \\
\hline $\mathrm{M}+\mathrm{C}$ & $22,2 \mathrm{a}$ & $25,2 \mathrm{a}$ & $26,2 \mathrm{a}$ & $26,1 \mathrm{a}$ & $\hat{\mathrm{y}}=22,591+0,034 \mathrm{x}^{* *}$ & 0,90 \\
\hline \multicolumn{7}{|c|}{ Comprimento de espiga $(\mathrm{mm})(2010 / 2011)$} \\
\hline Milheto & $149,4 \mathrm{~b}$ & $160,1 \mathrm{a}$ & $163,2 \mathrm{a}$ & 167,6 a & $\hat{y}=149,91+0,151 x^{* *}$ & 0,99 \\
\hline Crotalária & 157,9 a & 166,5 a & 165,4 a & 166,3 a & $\hat{\mathrm{y}}=159,36+0,069 \mathrm{x}^{* *}$ & 0,74 \\
\hline $\mathrm{M}+\mathrm{C}$ & 160,6 a & 163,9 a & 165,2 a & $166,2 \mathrm{a}$ & $\hat{y}=160,78+0,047 x^{* *}$ & 0,99 \\
\hline \multicolumn{7}{|c|}{ Massa de 1.000 grãos (g) (2009/2010) } \\
\hline Milheto & $263,7 \mathrm{~b}$ & $279,0 \mathrm{~b}$ & $283,6 \mathrm{~b}$ & $290,0 \mathrm{a}$ & $\hat{y}=264,39+0,218 x^{* *}$ & 0,99 \\
\hline Crotalária & $292,5 \mathrm{a}$ & $292,0 \mathrm{a}$ & 298,1 a & $295,2 \mathrm{a}$ & $\hat{\mathrm{y}}=\overline{\mathrm{y}}=294,4$ & - \\
\hline$-\mathrm{M}+\mathrm{C}$ & $288,6 \mathrm{a}$ & $294,1 \mathrm{a}$ & 296,3 a & 299,2 a & $\hat{\mathrm{y}}=288,65+0,087 \mathrm{x}^{* *}$ & 0,99 \\
\hline \multicolumn{7}{|c|}{ Massa de 1.000 grãos (g) (2010/2011) } \\
\hline Milheto & $267,9 \mathrm{~b}$ & $279,8 \mathrm{~b}$ & 287,0 a & $290,0 \mathrm{a}$ & $\hat{y}=268,31+0,191 x^{* *}$ & 0,99 \\
\hline Crotalária & $292,8 \mathrm{a}$ & 299,3 a & $296,0 \mathrm{a}$ & $292,3 \mathrm{a}$ & $\hat{y}=293+0,2 x-0,002 x^{2} *$ & 0,96 \\
\hline $\mathrm{M}+\mathrm{C}$ & 296,7 a & $294,1 \mathrm{a}$ & 298,4 a & 301,7 a & $\hat{y}=\bar{y}=297,7$ & - \\
\hline \multicolumn{7}{|c|}{ Produtividade $\left(\mathrm{kg} \mathrm{ha}^{-1}\right)(2009 / 2010)$} \\
\hline Milheto & $4.516 \mathrm{~b}$ & $5.359 \mathrm{~b}$ & $5.913 \mathrm{~b}$ & $6.350 \mathrm{a}$ & $\hat{\mathrm{y}}=4.494+15,41 \mathrm{x}^{* *}$ & 0,99 \\
\hline Crotalária & $5.941 \mathrm{a}$ & $6.706 \mathrm{a}$ & $6.372 \mathrm{ab}$ & $6.714 \mathrm{a}$ & $\hat{y}=6.051+5,656 x^{* *}$ & 0,63 \\
\hline $\mathrm{M}+\mathrm{C}$ & $5.620 \mathrm{a}$ & $6.404 \mathrm{a}$ & $6.611 \mathrm{a}$ & $6.599 \mathrm{a}$ & $\hat{y}=5.727+8,611 x^{* *}$ & 0,89 \\
\hline \multicolumn{7}{|c|}{ Produtividade $\left(\mathrm{kg} \mathrm{ha}^{-1}\right)(2010 / 2011)$} \\
\hline Milheto & $5.217 \mathrm{~b}$ & $6.828 \mathrm{~b}$ & $7.324 \mathrm{~b}$ & $8.019 \mathrm{a}$ & $\hat{y}=5.283+23,16 x^{* *}$ & 0,99 \\
\hline Crotalária & $7.355 \mathrm{a}$ & $7.957 \mathrm{a}$ & 8.187 a & $8.375 \mathrm{a}$ & $\hat{y}=7.388+8,604 x^{* *}$ & 0,99 \\
\hline $\mathrm{M}+\mathrm{C}$ & $6.905 \mathrm{a}$ & $7.733 \mathrm{a}$ & $8.158 \mathrm{a}$ & $8.431 \mathrm{a}$ & $\hat{y}=6.932+12,96 x^{* *}$ & 0,99 \\
\hline
\end{tabular}

M+C: milheto + crotalária. Teste $\mathrm{F}: * *$ e * significativo a 1 e $5 \%$, respectivamente. Médias seguidas por mesma letra nas colunas não diferem pelo teste de Tukey a $5 \%$.

aumento na absorção de $\mathrm{N}$ pelas plantas. Tal como era esperado, o teor de $\mathrm{N}$ foliar aumentou de modo linear com a elevação nas doses de N, após os três sistemas de manejo do solo, sugerindo que o manejo somente não propiciou condições capazes de fornecer $\mathrm{N}$ ao milho em quantidades satisfatórias, face à resposta da cultura à alteração da dose do nutriente. Avaliando o efeito de doses de $\mathrm{N}$ em cobertura $(0,25$, 50,100 e $150 \mathrm{~kg} \mathrm{ha}^{-1}$ ), na cultura do milho sob sistema plantio direto, Gomes et al. (2007) também verificaram incremento linear no teor de $\mathrm{N}$ foliar no florescimento da cultura com o aumento na dose do nutriente. Semelhante aos teores obtidos por Lourente et al. (2007), o N foliar variou de 15,92 a $27,71 \mathrm{~g} \mathrm{~kg}^{-1} \mathrm{em}$ razão dos fatores considerados.

O DC não foi influenciado pelas coberturas vegetais em ambos os anos agrícolas (Quadro 4). No entanto, quando a crotalária antecedeu o milho ao ano agrícola 
2009/2010, constatou-se maior CE (Quadro 5), apesar de não ter ocorrido diferença em relação ao cultivo de milheto + crotalária, o que pode estar relacionado à maior disponibilidade de $\mathrm{N}$ e $\mathrm{P}$, propiciada pela crotalária. Nesse ano de cultivo, o manejo do solo com $\mathrm{E}+\mathrm{GL}$ e com GP+GL favoreceu a obtenção de plantas com maior DC e CE. À medida que se aumentaram as doses de N, em ambos os anos de cultivo, constatouse incremento linear no DC. O aumento do DC com as doses de $\mathrm{N}$ evidenciou-se vantajoso, pois essa característica morfológica é uma das que mais tem sido relacionada com o percentual de quebramento de planta na cultura do milho. Além disso, o DC é muito importante para obtenção de alta produtividade, pois quanto maior o seu diâmetro, maior a capacidade da planta em armazenar fotoassimilados que contribuirão com o enchimento dos grãos (Kappes et al., 2011). O aumento no $\mathrm{DC}$ em resposta às alterações nas doses de N no milho também foi constatado por Cruz et al. (2008) e por Lana et al. (2009).

A elevação nas doses de $\mathrm{N}$ em cobertura resultou em incremento linear do CE no ano agrícola 2009/ 2010 (Quadro 5), corroborando os resultados obtidos por Lourente et al. (2007). O maior CE verificado na dose de $120 \mathrm{~kg} \mathrm{ha}^{-1}$ de $\mathrm{N}$ representou, em relação à ausência de $\mathrm{N}$ em cobertura, acréscimo de 8,7\%. De modo similar, Soares et al. (2003) verificaram que a aplicação de $120 \mathrm{~kg} \mathrm{ha}^{-1}$ de $\mathrm{N}$ no estádio $\mathrm{V}_{5}$, na forma de ureia, ocasionou aumento médio de $22 \%$ no $\mathrm{CE}$, em relação aos tratamentos sem a aplicação de N. Na ausência de fornecimento de $\mathrm{N}$ em cobertura no ano agrícola 2010/2011, a utilização de crotalária e de milheto + crotalária ocasionou maior CE (Quadro 6). Quando não se aplicou N em cobertura, o SPD proporcionou maior $\mathrm{CE}$ no último ano de cultivo (Quadro 8). Houve aumento linear do CE em razão das doses crescentes de $\mathrm{N}$ após as coberturas vegetais e sistemas de manejo do solo, exceto para o SPD.

Quadro 7. Massa de 1.000 grãos e produtividade do milho em razão de coberturas vegetais e sistemas de manejo do solo (2010/2011)

\begin{tabular}{lccc}
\hline \multirow{2}{*}{ Cobertura vegetal } & \multicolumn{3}{c}{ Manejo do solo $^{(1)}$} \\
\cline { 2 - 4 } & E+GL & GP+GL & SPD \\
\hline \multirow{3}{*}{ Milheto } & $282,4 \mathrm{bAB}$ & $275,4 \mathrm{bB}$ & $285,7 \mathrm{bA}$ \\
Crotalária & $295,1 \mathrm{aAB}$ & $287,2 \mathrm{aB}$ & $302,9 \mathrm{aA}$ \\
Milheto + crotalária & $290,0 \mathrm{abB}$ & $296,3 \mathrm{aB}$ & $306,8 \mathrm{aA}$ \\
& \multicolumn{3}{c}{ Produtividade $\left(\mathrm{kg}^{-1} \mathrm{ha}^{-1}\right)$} \\
Milheto & $6.815 \mathrm{bA}$ & $6.953 \mathrm{bA}$ & $6.773 \mathrm{bA}$ \\
Crotalária & $7.885 \mathrm{aA}$ & $7.813 \mathrm{aA}$ & $8.207 \mathrm{aA}$ \\
Milheto + crotalária & $7.278 \mathrm{abB}$ & $7.847 \mathrm{aAB}$ & $8.295 \mathrm{aA}$ \\
\hline
\end{tabular}

(1) E+GL: preparo com escarificador + grade "leve". GP+GL: preparo com grade "pesada" + grade "leve". SPD: sistema plantio direto. Médias seguidas por mesma letra minúscula nas colunas e maiúscula nas linhas não diferem pelo teste de Tukey a $5 \%$.
Em ambos os anos agrícolas, o DE não foi influenciado pelas coberturas vegetais e pelos sistemas de manejo do solo (Quadro 5). Porém, o aumento nas doses de N proporcionou acréscimo linear no $\mathrm{DE}$, discordando dos resultados obtidos por Ohland et al. (2005), que não verificaram diferença para o $\mathrm{DE}$ do milho em razão de doses de N em cobertura. O NFG não foi influenciado pelos fatores considerados nos dois anos de cultivo (Quadro 5), demonstrando que essa característica pode estar mais relacionada ao fator genótipo do que às práticas de manejo utilizadas na cultura.

Exceto para $120 \mathrm{~kg} \mathrm{ha}^{-1}$ de N, para as demais doses no ano agrícola 2009/2010, a utilização de crotalária e de milheto + crotalária propiciou maior MMG (Quadro 6), comprovando novamente os efeitos benéficos da crotalária (Ohland et al., 2005; Kappes, 2011) e ratificando os resultados obtidos por Silva et al. (2006), em que a MMG foi superior no milho cultivado após a crotalária, comparado ao cultivado após o milheto e o solo em pousio. A MMG, nesse ano de cultivo, aumentou linearmente com a elevação nas doses de $\mathrm{N}$, quando as culturas antecedentes foram $\mathrm{o}$ milheto e o milheto + crotalária. Resultados semelhantes foram obtidos por Silva et al. (2006) e por Lana et al. (2009), os quais verificaram aumento na massa de grãos do milho com o incremento nas doses de $\mathrm{N}$ em cobertura. $\mathrm{Na}$ ausência de fornecimento de $\mathrm{N}$ em cobertura e na aplicação de $60 \mathrm{~kg} \mathrm{ha}^{-1}$ de $\mathrm{N}$, no ano agrícola 2010/2011, o cultivo de crotalária e de milheto + crotalária resultou em maior MMG. Quando se aplicaram 90 e $120 \mathrm{~kg} \mathrm{ha}^{-1}$ de $\mathrm{N}$, não se obteve diferença entre as coberturas vegetais no que se refere à MMG. $\mathrm{O}$ incremento nas doses de $\mathrm{N}$, nesse ano de cultivo, ocasionou aumento linear da MMG, quando a cultura antecedente foi o milheto, resposta justificada pela alta relação $\mathrm{C} / \mathrm{N}$, pelo alto teor de lignina de seus resíduos e pela maior imobilização do $\mathrm{N}$ na biomassa microbiana (Alva et al., 2006), tornando o milho responsivo à aplicação de N. Entretanto, quando o antecedente foi a crotalária, houve comportamento quadrático da MMG em resposta ao aumento nas doses de $\mathrm{N}$, demonstrando que nessa situação ocorre menor exigência de doses elevadas de $\mathrm{N}$ em cobertura. Perante a equação de regressão, a máxima MMG foi estimada em 298,0 g com a aplicação de $50 \mathrm{~kg} \mathrm{ha}^{-1}$ de N. Nos três sistemas de manejo do solo, no ano agrícola 2010/2011, verificou-se maior MMG com o cultivo de crotalária e de milheto + crotalária (Quadro 7), apesar de no manejo com E+GL não se obteve diferença entre milheto + crotalária e milheto exclusivo. Em todas as coberturas vegetais, o SPD favoreceu maior MMG, embora não tenha ocorrido diferença em comparação ao manejo do solo com $\mathrm{E}+\mathrm{GL}$, quando as antecessoras foram o milheto e a crotalária exclusivos.

A crotalária e o milheto + crotalária proporcionaram, em ambos os anos agrícolas, maior produtividade de milho em todas as doses, exceto para $120 \mathrm{~kg} \mathrm{ha}^{-1}$ de $\mathrm{N}$ em que não se obteve diferença entre as coberturas (Quadro 6). A menor produtividade após o milheto pode 
Quadro 8. Teor de $\mathbf{N}$ foliar no florescimento e comprimento de espiga de milho em função de sistemas de manejo do solo e doses de $\mathrm{N}$ em cobertura (2010/2011)

\begin{tabular}{|c|c|c|c|c|c|c|}
\hline \multirow{2}{*}{ Manejo do solo ${ }^{(1)}$} & \multicolumn{4}{|c|}{ Dose de N $\left(\mathrm{kg} \mathrm{ha}^{-1}\right)$} & \multirow{2}{*}{ Equação de regressão } & \multirow{2}{*}{$\mathbf{R}^{2}$} \\
\hline & $\mathbf{0}$ & 60 & 90 & 120 & & \\
\hline \multicolumn{7}{|c|}{ Teor de $\mathrm{N}$ foliar $\left(\mathrm{g} \mathrm{kg}^{-1}\right)$} \\
\hline $\mathrm{E}+\mathrm{GL}$ & 19,9 a & $24,7 \mathrm{a}$ & $25,5 \mathrm{ab}$ & $26,2 \mathrm{a}$ & $\hat{y}=20,469+0,053 x^{* *}$ & 0,92 \\
\hline $\mathrm{GP}+\mathrm{GL}$ & $20,7 \mathrm{a}$ & $24,5 \mathrm{a}$ & $25,9 \mathrm{a}$ & $26,6 \mathrm{a}$ & $\hat{y}=21,011+0,051 x^{* *}$ & 0,97 \\
\hline SPD & $21,1 \mathrm{a}$ & $23,1 \mathrm{a}$ & $24,0 \mathrm{~b}$ & $24,7 \mathrm{a}$ & $\hat{y}=21,174+0,030 x^{* *}$ & 0,99 \\
\hline \multicolumn{7}{|c|}{ Comprimento de espiga (mm) } \\
\hline $\mathrm{E}+\mathrm{GL}$ & $154,1 \mathrm{~b}$ & $165,7 \mathrm{a}$ & $163,2 \mathrm{a}$ & $168,4 \mathrm{a}$ & $\hat{y}=155,40+0,110 x^{* *}$ & 0,83 \\
\hline $\mathrm{GP}+\mathrm{GL}$ & $152,2 \mathrm{~b}$ & $163,5 \mathrm{a}$ & $164,7 \mathrm{a}$ & $166,5 \mathrm{a}$ & $\hat{y}=153,61+0,121 x^{* *}$ & 0,91 \\
\hline SPD & $161,7 \mathrm{a}$ & $161,2 \mathrm{a}$ & $165,9 \mathrm{a}$ & $165,2 \mathrm{a}$ & $\hat{\mathrm{y}}=\overline{\mathrm{y}}=163,5$ & - \\
\hline
\end{tabular}

(1) E+GL: preparo com escarificador + grade "leve". GP+GL: preparo com grade "pesada" + grade "leve". SPD: sistema plantio direto. Teste F: **: significativo a $1 \%$. Médias seguidas por mesma letra nas colunas não diferem pelo teste de Tukey a $5 \%$.

ser atribuída à alta relação $\mathrm{C} / \mathrm{N}$ de seus resíduos e à maior imobilização do $\mathrm{N}$ na biomassa microbiana (Alva et al., 2006), com consequente redução da disponibilidade de $\mathrm{N}$ para o milho, tornando fundamental o fornecimento de $\mathrm{N}$ e a elevação nas doses de $\mathrm{N}$ em cobertura. Constatações similares foram relatadas nos estudos do manejo do $\mathrm{N}$ no milho desenvolvidos por Silva et al. (2006) e por Francisco et al. (2011). O milho, semeado após as coberturas, teve a sua produtividade incrementada linearmente à medida que se elevaram as doses de $\mathrm{N}$ nos dois anos de cultivo. Verifica-se que quando o milheto foi a cultura antecessora, o milho teve sua produtividade incrementada em 15,41 e 23,16 kg ha ${ }^{-1}$ para cada kg $\mathrm{ha}^{-1}$ de $\mathrm{N}$ aplicado em cobertura nos anos agrícolas 2009/2010 e 2010/2011, respectivamente, sendo, portanto, mais responsivo ao $\mathrm{N}$ em relação à crotalária e o milheto + crotalária. Isso indicou que o aumento nas doses de $\mathrm{N}$ foi menos eficiente para incrementar a produtividade, quando as antecessoras foram a crotalária e o milheto + crotalária. Em cinco dos quatro híbridos de milho avaliados, Cruz et al. (2008) também verificaram aumento linear de produtividade em razão do incremento nas doses de $\mathrm{N}$ em cobertura, quando a cultura antecedente foi a $C$. juncea.

Condizente ao verificado com a MMG, no ano agrícola 2010/2011, a utilização de crotalária e de milheto + crotalária proporcionou maior produtividade do milho nos três sistemas de manejo, exceto quando se manejou o solo com E+GL, onde não se constatou diferença entre o milheto + a crotalária e o cultivo de milheto exclusivo (Quadro 7). O resultado constatado no SPD discorda dos obtidos por Sousa Neto et al. (2008), os quais não observaram diferença de produtividade do milho cultivado em SPD, após crotalária e milheto. Houve diferença entre manejo do solo somente quando milheto + crotalária antecederam o milho, obtendo-se maior produtividade no SPD, apesar de não ter ocorrido diferença entre esse sistema e o manejo com GP+GL. As produtividades deste estudo foram condizentes às médias obtidas com o milho de primeira safra nos anos agrícolas 2009/2010 e 2010/2011, no Estado do Mato Grosso do Sul, as quais foram de 6.535 e $6.700 \mathrm{~kg} \mathrm{ha}^{-1}$, respectivamente (CONAB, 2011).

Considerando o alto custo dos fertilizantes nitrogenados e a necessidade de uma agricultura sustentável, a utilização da crotalária pode ser ótima alternativa para o suprimento de $\mathrm{N}$ ao milho, face à constatação de resultados positivos sobre a produtividade do milho neste trabalho. Algumas coberturas vegetais possuem a capacidade de aumentar a disponibilidade de nutrientes e, em especial, de N, para a cultura em sucessão, quer seja por meio do manejo da sua biomassa ou pela fixação biológica do $\mathrm{N}$ atmosférico.

É possível que a elevada quantidade de matéria seca produzida, com elevado acúmulo de $\mathrm{N}$ e $\mathrm{P}$ na crotalária e no consórcio milheto + crotalária, associada à menor relação $\mathrm{C} / \mathrm{N}$, comparativamente ao milheto, resultou em rápida disponibilização desses nutrientes ao solo e menor imobilização de N mineral, o que, consequentemente, tenham contribuído para a maior produtividade de milho. O contrário é válido quando a cultura antecessora foi o milheto. Portanto, é oportuno ressaltar a importância da relação $\mathrm{C} / \mathrm{N}$ da cobertura vegetal durante a sua escolha.

Nas condições edafoclimáticas do Cerrado, a incorporação dos resíduos culturais com E+GL e GP+GL acelera a sua velocidade de decomposição e, consequentemente, aumenta os teores de $\mathrm{N}$ no solo e o aproveitamento desse pela cultura do milho. Entretanto, estudos adicionais sobre o comportamento do $\mathrm{N}$ do solo, sob diferentes manejos no Cerrado, precisam ser realizados.

A resposta linear crescente em razão da adubação nitrogenada em cobertura, demonstrada pela maioria das características mensuradas, vem ressaltar o papel importante do $\mathrm{N}$ no desempenho agronômico das plantas e nos componentes de produção, ao mesmo 
tempo em que revela que as doses aplicadas em cobertura não foram suficientes para obtenção da máxima produtividade.

\section{CONCLUSÕES}

1. O incremento linear do ICF, do teor de $\mathrm{N}$ foliar, do comprimento e do diâmetro de espiga, da massa de 1.000 grãos e da produtividade ocorre com o aumento nas doses de $\mathrm{N}$ em cobertura.

2. A utilização de crotalária e de milheto + crotalária como antecessores, associada à aplicação de $120 \mathrm{~kg} \mathrm{ha}^{-1} \mathrm{de} \mathrm{N}$ em cobertura do milho, proporciona maior produtividade de grãos.

\section{AGRADECIMENTO}

À Fundação de Amparo à Pesquisa do Estado de São Paulo - FAPESP, pela bolsa de estudo concedida ao primeiro autor.

\section{LITERATURA CITADA}

AITA, C. \& GIACOMINI, S.J. Matéria orgânica do solo, nitrogênio e enxofre nos diversos sistemas de exploração agrícola. In: YAMADA, T.; ABDALLA, S.R.S. \& VITTI, G.C., eds. Nitrogênio e enxofre na agricultura brasileira. Piracicaba, IPNI Brasil, 2007. p.1-42.

ALVA, A.K.; PARAMASIVAM, S.; FARES, A.; DELGADO, J.A.; MATTOS JR, D. \& SAJWAN, K. Nitrogen and irrigation management practices to improve nitrogen uptake efficiency and minimize leaching losses. J. Crop Improv., 15:369-420, 2006.

ANDRADE, A.C.; FONSECA, D.M.; QUEIROZ, D.S.; SALGADO, L.T. \& CECON, P.R. Adubação nitrogenada e potássica em capim-elefante (Pennisetum purpureum Schum. cv. Napier). Ci. Agrotec., p.1643-1651, 2003. (Edição Especial)

ARGENTA, G.; SILVA, P.R.F.; FOSTHOFER, E.L.; STRIEDER, M.L.; SUHRE, E. \& TEICHMANN, L.L. Adubação nitrogenada em milho pelo monitoramento do nível de nitrogênio na planta por meio do clorofilômetro. R. Bras. Ci. Solo, 27:109-119, 2003.

BELARMINO, M.C.J.; PINTO, J.C.; ROCHA, G.P.; FURTINI NETO, A.E. \& MORAIS, A.R. Altura de perfilho e rendimento de matéria seca de capim-tanzânia em função de diferentes doses de superfosfato simples e sulfato de amônio. Ci. Agrotec., 27:879-885, 2003.

CARVALHO, I.Q.; SILVA, M.J.S.; PISSAIA, A.; PAULETTI, V. \& POSSAMAI, J.C. Espécies de cobertura de inverno e nitrogênio na cultura do milho em sistema de plantio direto. Sci. Agric., 8:179-184, 2007.
CENTURION, J.F. Balanço hídrico da região de Ilha Solteira. Científica, 10:57-61, 1982.

COMPANHIA NACIONAL DE ABASTECIMENTO CONAB. Acompanhamento de safra brasileira: Grãos, nono levantamento, junho/2011. Brasília, 2011. 47p.

CRUZ, S.C.S.; PEREIRA, F.R.S.; SANTOS, J.R.; ALBUQUERQUE, A.W. \& PEREIRA, R.G. Adubação nitrogenada para o milho cultivado em sistema plantio direto, no Estado de Alagoas. R. Bras. Eng. Agríc. Amb., 12:62-68, 2008.

EMPRESA BRASILEIRA DE PESQUISA AGROPECUÁRIA EMBRAPA. Sistema brasileiro de classificação de solos. 2.ed. Rio de Janeiro, Embrapa Solos, 2006. 306p.

FIGUEIREDO, C.C.; RESCK, D.V.S.; GOMES, A.C. \& URQUIAGA, S. Sistemas de manejo na absorção de nitrogênio pelo milho em um Latossolo Vermelho no Cerrado. Pesq. Agropec. Bras., 40:279-287, 2005.

FRANCISCO, E.A.B.; ZANCANARO, L.; HILLESHEIM, J. \& $\mathrm{KOCH}$, C.V. Produtividade e eficiência de uso do nitrogênio pelo milho na região Sul de Mato Grosso. Inf. Téc. Fundação MT, 1:1-3, 2011.

GOMES, R.F.; SILVA, A.G.; ASSIS, R.L. \& PIRES, F.R. Efeito de doses e da época de aplicação de nitrogênio nos caracteres agronômicos da cultura do milho sob plantio direto. R. Bras. Ci. Solo, 31:931-938, 2007.

KAPPES, C.; ANDRADE, J.A.C.; ARF, O.; OLIVEIRA, A.C.; ARF, M.V. \& FERREIRA, J.P. Desempenho de híbridos de milho em diferentes arranjos espaciais de plantas. Bragantia, 70:334-343, 2011.

KAPPES, C. Utilizações e benefícios da crotalária na agricultura. R. Panorama Rural, 147:16-17, 2011.

KLUTHCOUSKI, J.; FANCELLI, A.L.; DOURADO NETO, D.; RIBEIRO, C.M. \& FERRARO, L.A. Manejo do solo e o rendimento de soja, milho, feijão e arroz em plantio direto. Sci. Agric., 57:97-104, 2000.

LANA, M.C.; WOYTICHOSKI JÚNIOR, P.P.; BRACCINI, A.L.; SCAPIM, C.A.; ÁVILA, M.R. \& ALBRECHT, L.P. Arranjo espacial e adubação nitrogenada em cobertura na cultura do milho. Acta Sci. Agron., 31:433-438, 2009.

LARA CABEZAS, W.A.R.; ALVES, B.J.R.; CABALLERO, S.S.U. \& SANTANA, D.G. Influência da cultura antecessora e da adubação nitrogenada na produtividade de milho em sistema plantio direto e solo preparado. Ci. Rural, 34:1005-1013, 2004.

LOURENTE, E.R.P.; ONTOCELLI, R.; SOUZA, L.C.F.; GONÇALVES, M.C.; MARCHETTI, M.E. \& RODRIGUES, E.T. Culturas antecessoras, doses e fontes de nitrogênio nos componentes de produção do milho. Acta Sci. Agron., 29:55-61, 2007.

MALAVOLTA, E.; VITTI, G.C. \& OLIVEIRA, S.A. Avaliação do estado nutricional das plantas: Princípios e aplicações. 2.ed. Piracicaba, Potafos, 1997. 319p.

OHLAND, R.A.A.; SOUZA, L.C.F.; HERNANI, L.C.; MARCHETTI, M.E. \& GONÇALVES, M.C. Culturas de cobertura do solo e adubação nitrogenada no milho em plantio direto. Ci. Agrotec., 29:538-544, 2005. 
RITCHIE, S.W.; HANWAY, J.J. \& BENSON, G.O. Como a planta de milho se desenvolve. Piracicaba, Potafos, 2003. 20p. (Informações Agronômicas, 103)

SANTOS, M.M.; GALVÃO, J.C.C.; SILVA, I.R.; MIRANDA, G.V. \& FINGER, F.L. Épocas de aplicação de nitrogênio em cobertura na cultura do milho em plantio direto, e alocação do nitrogênio $\left({ }^{15} \mathrm{~N}\right)$ na planta. R. Bras. Ci. Solo, 34:1185-1194, 2010.

SILVA, E.C.; MURAOKA, T.; BUZETTI, S. \& TRIVELIN, P.C.O. Manejo de nitrogênio no milho sob plantio direto com diferentes plantas de cobertura, em Latossolo Vermelho. Pesq. Agropec. Bras., 41:477-486, 2006.
SOARES, M.A.; DOURADO NETO, D. \& MANFRON, P.A. Nitrogênio, zinco e boro e suas respectivas interações no desempenho da cultura de milho. R. Plantio Direto, 76:2227, 2003.

SOUSA NETO, E.L.; ANDRIOLI, I.; BEUTLER, A.N. \& CENTURION, J.F. Atributos físicos do solo e produtividade de milho em resposta a culturas de pré-safra. Pesq. Agropec. Bras., 43:255-260, 2008.

STRIEDER, M.L.; SILVA, P.R.F.; ANGHINONI, I.; MEURER, E.J.; RAMBO, L. \& ENDRIGO, P.C. Época de aplicação da primeira dose de nitrogênio em cobertura em milho e espécies antecessoras de cobertura de inverno. R. Bras. Ci. Solo, 30:879-890, 2006. 